\title{
Closure of Petersen's defect in gastrectomy for gastric cancer: an interrupted time series analysis from a high-volume institution in China
}

\author{
Tao Pan ${ }^{1} \cdot$ Hui Wang ${ }^{1} \cdot$ Kai Liu $^{1} \cdot$ Xin-zu Chen ${ }^{1} \cdot$ Wei-han Zhang ${ }^{1} \cdot$ Xiao-long Chen ${ }^{1} \cdot$ Kun Yang ${ }^{1} \cdot$ Bo Zhang ${ }^{1}$. \\ Zong-guang Zhou ${ }^{1}$. Jian-kun $\mathrm{Hu}^{1}$
}

Received: 15 July 2020 / Accepted: 26 October 2020 / Published online: 5 November 2020

(C) The Author(s) 2020

\begin{abstract}
Purpose Petersen's hernia (PH) is a serious complication after gastrectomy for gastric cancer. The aim of this study was to investigate whether closure of Petersen's defect (PD) can decrease the rates of PH and suspected Petersen's hernia (SPH).

Methods Patients who underwent gastrectomy with PD were enrolled. From January 2014 to January 2017, we performed gastrectomy without PD closure (non-closure group). From February 2017 to June 2018, we closed PDs during gastrectomy (closure group). The rates of PH and SPH were compared between the two groups. The last follow-up was updated in August 2020.

Results Among a total of 1213 patients, 12 patients (1.0\%) developed PH, and 23 patients (1.9\%) developed SPH. The rate of PH in the closure group was significantly lower than that in the non-closure group $(1 / 385,0.3 \%$ versus $11 / 828,1.3 \%, p=0.042, \log$ rank test). The rate of SPH in the closure group was significantly lower than that in the non-closure group $(1 / 385,0.3 \%$ versus $22 /$ $828,2.7 \%, p=0.008$, log-rank test). Non-closure of PD was a risk factor for PH and SPH (odds ratio (OR) $7.72,95 \%$ CI 1.84 $32.35, p=0.006)$.

Conclusions PD closure is recommended after gastrectomy for gastric cancer, as the rates of PH and SPH were significantly decreased.
\end{abstract}

Keywords Gastric cancer · Petersen's hernia · Gastrectomy

\section{Introduction}

An internal hernia can lead to small bowel obstruction and life-threatening conditions, such as bowel ischemia or perforation $[1,2]$. Internal hernia is a recognized and well-described complication after laparoscopic Roux-Y gastric bypass [3-6]. However, there have been few studies about internal hernia after gastrectomy for gastric cancer [1, 7], and to our

Tao Pan and Hui Wang are co-authors.

Jian-kun $\mathrm{Hu}$

hujkwch@126.com

1 Department of Gastrointestinal Surgery and Laboratory of Gastric Cancer, State Key Laboratory of Biotherapy, West China Hospital, Sichuan University and Collaborative Innovation Center for Biotherapy, No. 37 GuoXue Xiang Street, Chengdu 610041, Sichuan Province, China knowledge, there has been no study on Petersen's hernia (PH) after gastrectomy for gastric cancer.

The low incidence and nonspecific manifestations of $\mathrm{PH}$ make it difficult to diagnose preoperatively [7-9]. Some nonoperatively managed patients are highly suspicious for $\mathrm{PH}$ according to manifestations and computed tomography (CT) scans $[10,11]$; however, some of these patients might be misdiagnosed as having adhesive small bowel obstructions and managed non-operatively [12, 13]. Patients with suspected Petersen's hernia (SPH) may have nonspecific and recurrent abdominal pain; they are also at risk of incarcerated internal hernia and bowel necrosis; therefore, great attention should be paid to these patients.

Closure of Petersen's defect (PD) is now recommended for laparoscopic Roux-Y gastric bypass [2, 5]. However, PH can occur despite the closure of PDs [14]. There is also concern that closure by itself may increase the risk of bleeding, mesenteric hematoma, and anastomotic leakage due to vascular injury [3]. PDs are also created in Billroth-2 (B-2) and Roux- 
en-Y (R-Y) reconstructions after gastrectomy for gastric cancer. However, to date, there has been no consensus on the management of PD after gastrectomy for gastric cancer.

Therefore, the purpose of our study was to investigate whether PD closure during gastrectomy can decrease the rates of PH and SPH. To our knowledge, this was the first study to specifically investigate the rate of $\mathrm{PH}$ following gastrectomy for gastric cancer. We also included SPH as an endpoint in this study.

\section{Materials and methods}

\section{Ethical statement}

The study was based on information collected from the Surgical Gastric Cancer Patient Registry of West China Hospital (WCH-SGCPR-2019-10). The establishment of the database was approved by the Research Ethics Committee of West China Hospital. Additionally, because this was an interrupted time series study [15], patients did not provide written informed consent, but personal information was anonymized before analysis.

\section{Patients}

A total of 1213 consecutive patients with gastric cancer treated from January 2014 to June 2018 in West China Hospital were eligible for the study. The diagnosis of gastric cancer was confirmed in all patients by upper gastrointestinal endoscopy and biopsy. The inclusion criteria were as follows: (1) patients with histologically proven gastric adenocarcinomas and (2) patients who underwent curative distal gastrectomy with B-2 reconstruction and total gastrectomy with ante-colic $\mathrm{R}-\mathrm{Y}$ reconstruction. The exclusion criteria were as follows: (1) other types of malignancies of the stomach; (2) palliative surgery; (3) previous history of gastrectomy; (4) lost to follow-up. A flowchart of the patients enrolled in the study is shown in Fig. 1.

\section{Clinicopathological materials}

Clinicopathological data including sex, age, body mass index (BMI), previous abdominal surgery, surgical approach, reconstruction type (distal gastrectomy with B-2 anastomosis or total gastrectomy with ante-colic R-Y anastomosis), extent of lymphadenectomy, tumor diameter, tumor location, macroscopic type, tumor differentiation, pathologic TNM stage, and postoperative adjuvant chemotherapy were evaluated. All definitions, including the macroscopic type, tumor differentiation, and TNM stage, were determined according to the 7 th Staging Manual of the American Joint Committee on Cancer [16].

\section{Surgical technique}

The surgical treatment principles were based on the Japanese Gastric Cancer Treatment Guidelines [17, 18]. For reconstruction, B-2 reconstruction was adopted for distal gastrectomy and ante-colic R-Y reconstruction was adopted for total gastrectomy. Jejunojejunostomy mesenteric defects were all closed for patients who underwent R-Y reconstruction in both groups. From January 2014 to January 2017, we performed R$\mathrm{Y}$ and B-2 reconstruction without closure of PDs (non-closure group). From February 2017 to June 2018, we closed PDs for both R-Y and B-2 reconstruction (closure group). We closed all defects using an interrupted 3-0 non-absorbable suture (Fig. 2a, b).

\section{Follow-up}

It was recommended that all patients be examined every 3 months in the first 2 years, every 6 months in the third year, and at least once a year in the following years. A complete blood count and chemistry file were performed during every follow-up. CT examination of the chest, abdomen, and pelvis was performed every 6 months in the first 3 years and at least once a year thereafter. Upper endoscopy was performed every 6 months for the first year, annually from the second to the fifth year, and as clinically indicated thereafter. However, in emergency situations (such as acute abdominal pain), we recommend that the patient be examined and treated at the hospital immediately.

Among all the patients in the present study, 985 (77.9\%) patients had examinations in our hospital. These patients went to our outpatient clinic after the examination. The outpatient doctors recorded the results of the abnormal tests and updated them in our gastric cancer database. Details of these examinations can be also obtained through our electronic system when needed. In our present study, $268(22.1 \%)$ patients had examinations in other hospitals. Our doctors and members of the Volunteer Team of Gastric Cancer Surgery in our hospital made a telephone call to all the patients every 6 months. So, for all the patients, their records can be updated at least twice a year. Postoperative follow-up was mainly performed either at the postoperative outpatient clinic or by telephone. In recent years, we have started using WeChat as a supplement. We asked all our patients or their families to join our patient contact group on WeChat after gastrectomy. For those who had examinations in other hospitals and could not provide accurate information by telephone, we asked them to come to our outpatient clinic or upload their inpatient records and examinations through our patient contact group on WeChat.

Follow-up information was also collected from the database and updated on August 1, 2020. The duration of follow-up was recorded as the time from gastrectomy until 
Fig. 1 The flowchart of patients enrolled in the study

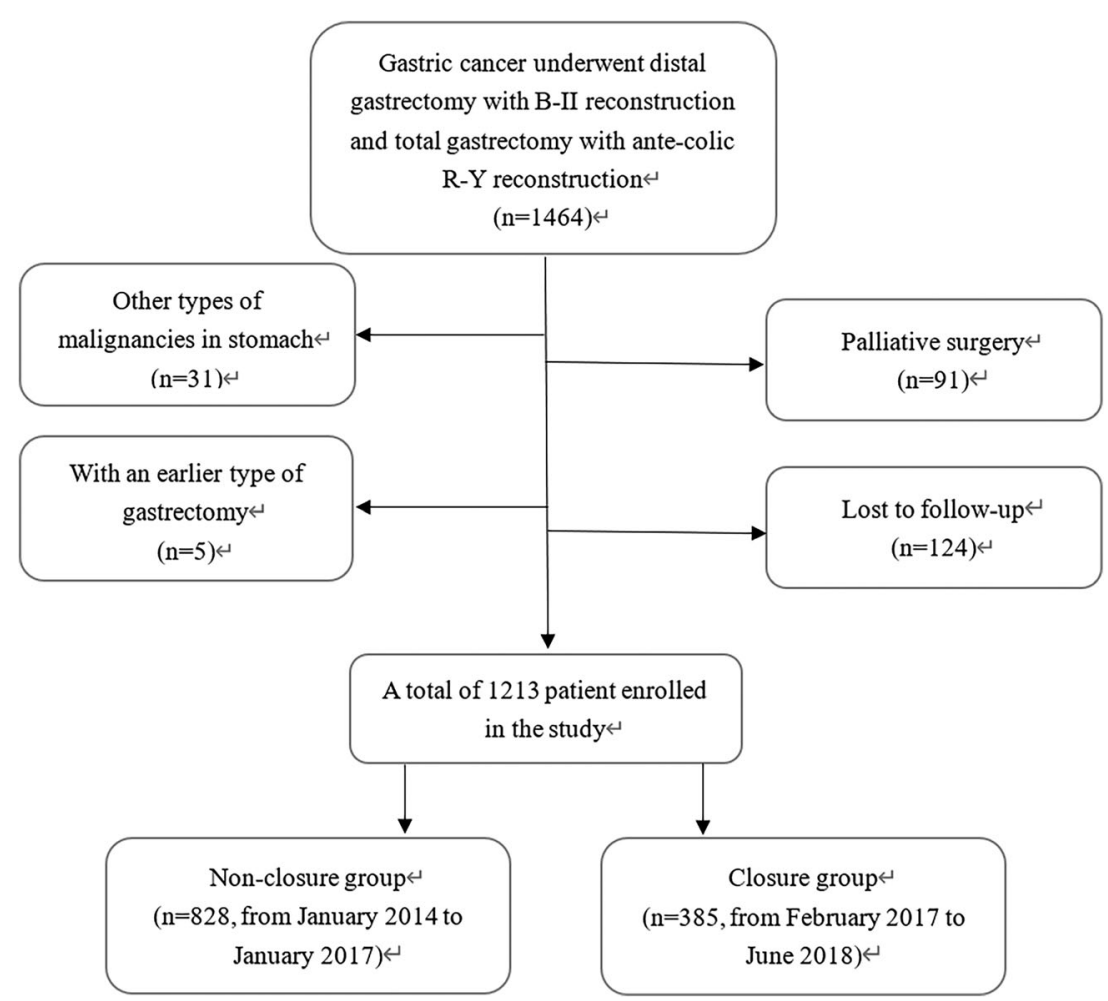

death or the last registered follow-up at the postoperative outpatient clinic or by telephone, whichever came first.

\section{Endpoints}

The primary endpoints were $\mathrm{PH}$ and SPH. The secondary endpoints were postoperative complications within 30 days of gastrectomy.

PH was defined as an internal hernia located at the PD and was confirmed by surgical exploration.

SPH was defined as patients who showed small bowel obstruction and a whirling appearance of the mesentery on CT scans ("whirl sign", Fig. 3) after gastric cancer surgery. These patients were not confirmed by surgery. The "whirl sign" on the CT scan was confirmed by two radiologists and was described in previous studies [10,11, 19-21].

Early postoperative complications were classified according to the Clavien-Dindo surgical complication grading system [22]. When a patient had two or more postoperative complications, the higher grade was recorded [23].

\section{Statistical analysis}

Categorical variables are presented as numbers with percentages, and continuous data are presented as means with the standard deviation (SD). Categorical data were compared with the Pearson $\chi^{2}$ test or Fisher's exact test, and continuous data were compared with an

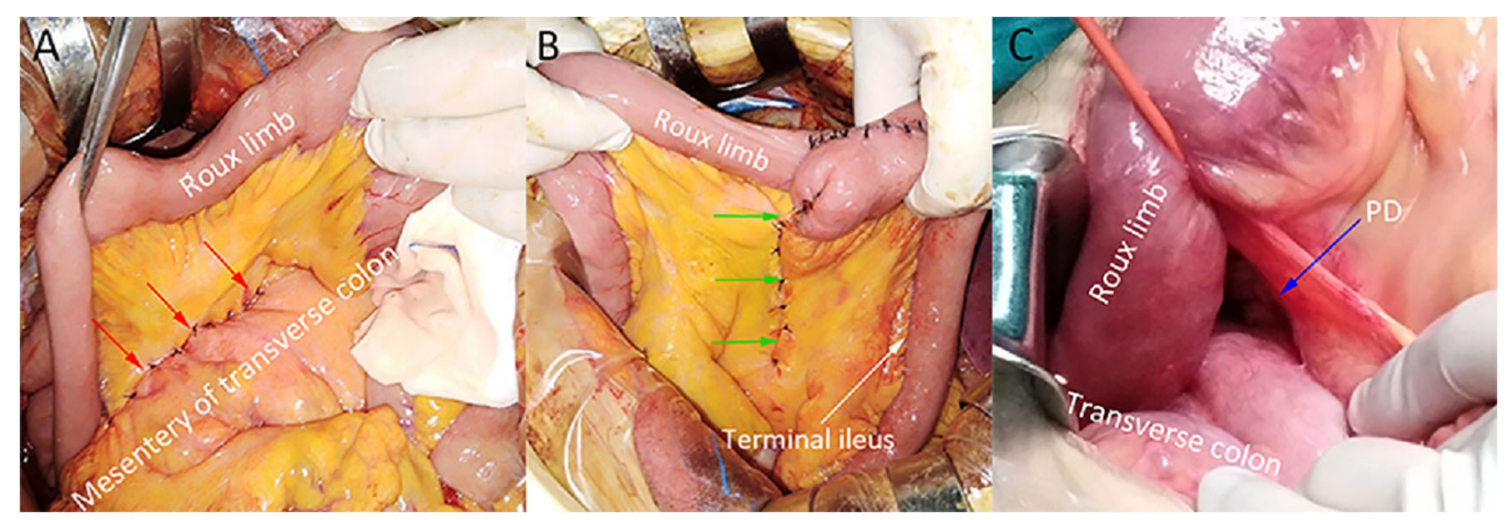

Fig. 2 Operative pictures. a Closure of Petersen's defect (PD, red arrows). b Closure of jejunojejunostomy mesenteric defect (green arrows). $\mathbf{c}$ PD (blue arrow) was found open after reduction of the Petersen's hernia (PH) 


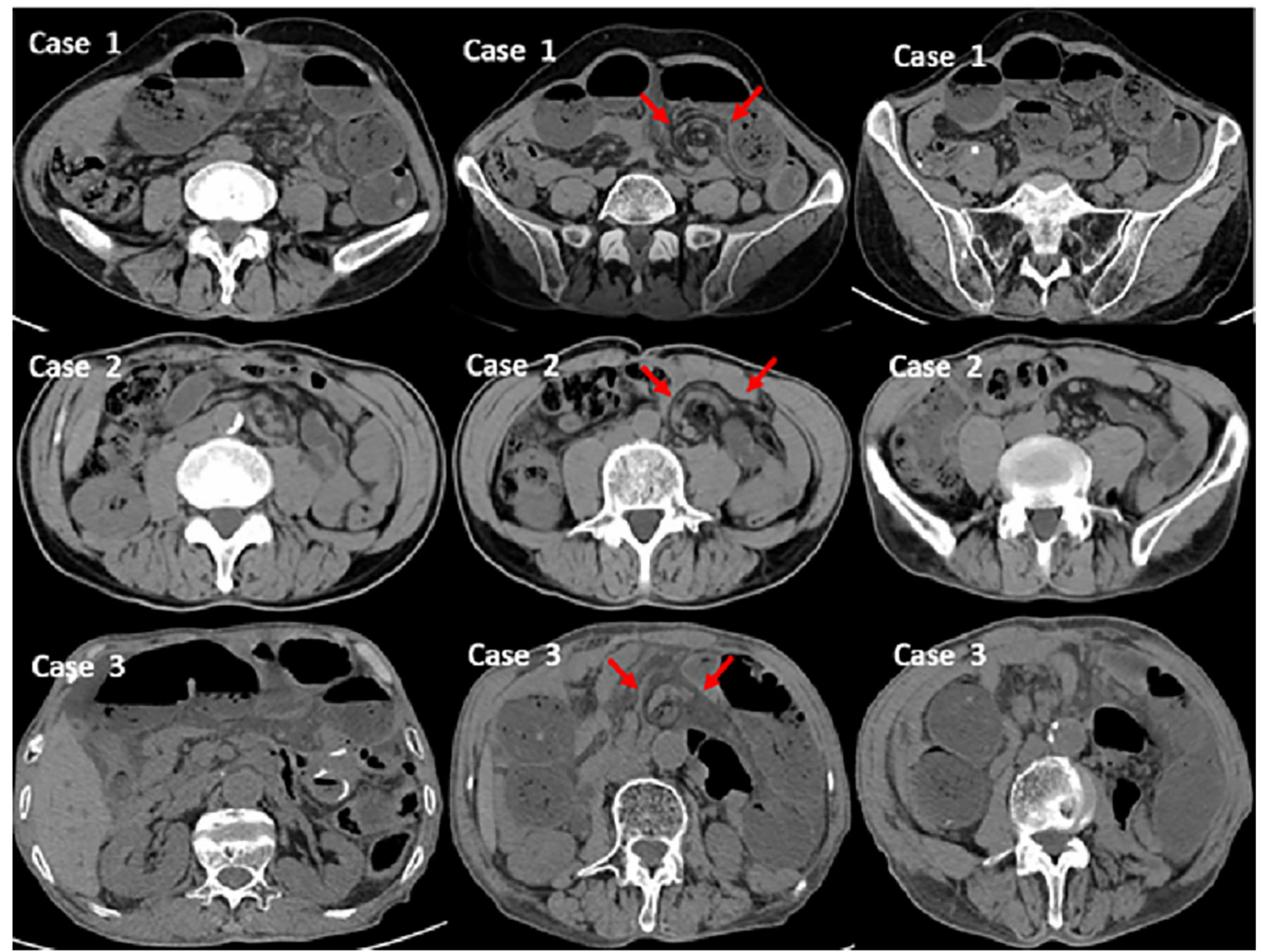

Fig. 3 Whirling appearance of the mesentery and mesenteric vessels on CT scans ("whirl sign", red arrows)

independent samples $t$ test or a Wilcoxon rank-sum test as appropriate. The rates of $\mathrm{PH}$ and $\mathrm{SPH}$ were compared between the two groups by a log-rank test. A logistic regression analysis was performed to test the univariate and multivariate associations between variables to identify risk factors for $\mathrm{PH}$ and SPH. A two-sided value of $p<0.050$ was considered significant. Data were analyzed using SPSS 20.0 statistical software (SPSS $®$, Chicago, IL, USA).

\section{Results}

\section{Baseline data}

A total of 1213 patients were enrolled in our study. The non-closure group included 828 patients, and the closure group included 385 patients. The demographic data of the entire patient population are presented in Table 1. There were no significant differences between the two groups with respect to sex, age, BMI, previous abdominal surgery, surgical approach, reconstruction type, extent of lymphadenectomy, tumor diameter, tumor location, macroscopic type, tumor differentiation, TNM stage, or postoperative adjuvant chemotherapy.

\section{Early postoperative complications}

Table 2 shows the detailed information of complications occurring within 30 days of gastrectomy. There was no significant difference between the two groups with respect to postoperative complications, non-surgical complications, or surgical complications $(p=0.457,0.571$, and 0.106 , respectively).

\section{Rates of PH and SPH}

Among a total of 1213 patients, 12 patients (1.0\%) developed $\mathrm{PH}$, and 23 patients (1.9\%) developed SPH. In the non-closure group, which included 828 patients, 11 patients $(1.3 \%)$ developed $\mathrm{PH}$, and 22 patients $(2.6 \%)$ developed SPH. The mean time intervals of $\mathrm{PH}$ and SPH were 14.4 and 11.3 months, respectively. After routine $\mathrm{PD}$ closure in 385 patients in the closure group, one patient $(0.3 \%)$ developed $\mathrm{PH}$ after 22 months, and one patient $(0.3 \%)$ developed SPH after 19 months. The rates of $\mathrm{PH}$ and $\mathrm{SPH}$ in the closure group were significantly lower than those in the non-closure group ( $p=$ 0.042 and 0.009 , respectively, log-rank test). 
Table 1 Demographic data at the time of gastrectomy

\begin{tabular}{|c|c|c|c|}
\hline & Non-closure group (first period, $N=828$ ) & Closure group (second period, $N=385$ ) & $p^{\dagger}$ \\
\hline Sex & & & 0.077 \\
\hline Male & $592(71.5 \%)$ & $256(66.5 \%)$ & \\
\hline Female & $236(28.5 \%)$ & $129(33.5 \%)$ & \\
\hline Mean age at operation (years)* & $58.0 \pm 11.4$ & $59.0 \pm 11.1$ & $0.077+$ \\
\hline Body mass index $\left(\mathrm{kg} / \mathrm{m}^{2}\right)^{*}$ & $22.6 \pm 2.9$ & $22.9 \pm 3.2$ & $0.089 \ddagger$ \\
\hline Previous abdominal surgery & & & 0.092 \\
\hline Yes & $137(16.5 \%)$ & $79(20.5 \%)$ & \\
\hline No & $691(83.5 \%)$ & $306(79.5 \%)$ & \\
\hline Surgical approach & & & 0.516 \\
\hline Open & $721(87.1 \%)$ & $330(85.7 \%)$ & \\
\hline Laparoscopy assisted & $107(12.9 \%)$ & $55(14.3 \%)$ & \\
\hline \multicolumn{4}{|l|}{ Reconstruction type } \\
\hline B-2 (distal gastrectomy) & $551(66.5 \%)$ & $257(66.8 \%)$ & 0.943 \\
\hline R-Y (total gastrectomy) & $277(33.5 \%)$ & $128(33.2 \%)$ & \\
\hline Extent of lymphadenectomy & & & 0.916 \\
\hline $\mathrm{D} 1 / \mathrm{D} 1+$ & $157(19.0 \%)$ & $73(19.0 \%)$ & \\
\hline $\mathrm{D} 2 / \mathrm{D} 2+$ & $671(81.0 \%)$ & $312(81.0 \%)$ & \\
\hline Tumor diameter $(\mathrm{cm})^{*}$ & $4.6 \pm 2.5$ & $4.4 \pm 2.5$ & $0.208+$ \\
\hline Tumor location & & & 0.813 \\
\hline Upper & $180(21.7 \%)$ & $87(22.6 \%)$ & \\
\hline Middle & $118(14.3 \%)$ & $59(15.3 \%)$ & \\
\hline Lower & $516(62.3 \%)$ & $231(60.0 \%)$ & \\
\hline Whole & $14(1.7 \%)$ & $8(2.1 \%)$ & \\
\hline \multicolumn{4}{|l|}{ Macroscopic type } \\
\hline Early gastric cancer & $182(22.0 \%)$ & $85(22.1 \%)$ & 0.761 \\
\hline Borrmann-1 & $17(2.1 \%)$ & $7(1.8 \%)$ & \\
\hline Borrmann-2 & $298(36.0 \%)$ & $140(36.4 \%)$ & \\
\hline Borrmann-3 & $282(34.1 \%)$ & $131(34.0 \%)$ & \\
\hline Borrmann-4 & $49(5.9 \%)$ & $22(5.7 \%)$ & \\
\hline Tumor differentiation & & & 0.307 \\
\hline Well/moderately & $226(27.3 \%)$ & $116(30.1 \%)$ & \\
\hline Poorly/undifferentiated & $602(72.7 \%)$ & $269(69.9 \%)$ & \\
\hline Pathological TNM stage & & & 0.568 \\
\hline $\mathrm{I}$ & $217(26.2 \%)$ & $102(26.5 \%)$ & \\
\hline II & $213(25.7 \%)$ & $109(28.3 \%)$ & \\
\hline III & $398(48.1 \%)$ & $174(45.2 \%)$ & \\
\hline Postoperative adjuvant chemotherapy & & & 0.649 \\
\hline Yes & $507(61.2 \%)$ & $241(62.6 \%)$ & \\
\hline No & $321(38.8 \%)$ & $144(37.4 \%)$ & \\
\hline
\end{tabular}

Values in parentheses are percentages unless indicated otherwise

*Values are mean \pm standard deviation. $R-Y$, Roux-en-Y reconstruction; $B-2$, Billroth-2 reconstruction

$\dagger \chi^{2}$ test, except $\ddagger$ paired $t$ test

\section{Characteristics of patients with PH}

Table 3 shows the characteristics of patients with PH. Eleven patients in the non-closure group and one patient in the closure group developed PH. The PD was found to be open during the operation (Fig. 1c). We closed all PDs after the reduction of the herniated bowels, and no $\mathrm{PH}$ recurrence was observed until the end of the study. All 12 patients showed "whirl signs" 
Table 2 Detailed information about complications within 30 days of gastrectomy

\begin{tabular}{|c|c|c|c|}
\hline & Non-closure group (first period) & Closure group (second period) & $p$ 半 \\
\hline Postoperative complications (total) ${ }^{-3}$ & $132(15.9 \%)$ & $55(14.3 \%)$ & 0.457 \\
\hline Non-surgical complications & $96(11.6 \%)$ & $49(12.7 \%)$ & 0.571 \\
\hline Pulmonary disease & $88(10.6 \%)$ & $43(11.2 \%)$ & \\
\hline Urinary disease & $5(0.6 \%)$ & $3(0.8 \%)$ & \\
\hline Cardiac disease & 0 & $1(0.3 \%)$ & \\
\hline Delirium & $2(0.2 \%)$ & $1(0.3 \%)$ & \\
\hline Venous thromboembolism & 0 & $1(0.3 \%)$ & \\
\hline Liver dysfunction & $1(0.1 \%)$ & 0 & \\
\hline Surgical complications & $43(5.2 \%)$ & $12(3.1 \%)$ & 0.106 \\
\hline Anastomotic/stump leakage & $5(0.6 \%)^{\alpha}$ & $1(0.3 \%)^{\#}$ & \\
\hline Surgical site infection & $10(1.4 \%)$ & $3(0.8 \%)$ & \\
\hline Pancreatic fistula & $3(0.4 \%)$ & $1(0.3 \%)$ & \\
\hline Lymphatic leakage & $1(0.1 \%)$ & 0 & \\
\hline Postoperative bleeding & $4(0.5 \%)^{\mathrm{II}}$ & $3(0.8 \%)^{x}$ & \\
\hline Delayed gastric emptying & $19(2.3 \%)$ & $4(1.0 \%)$ & \\
\hline Other major complications & $1(0.1 \%)^{\S}$ & 0 & \\
\hline Clavien-Dindo classification & & & 0.245 \\
\hline I-II & $125(15.1 \%)$ & $52(13.5 \%)$ & \\
\hline III-V & $6(0.8 \%)^{\star}$ & $3(0.8 \%)$ & \\
\hline
\end{tabular}

Values in parentheses are percentages

${ }^{3} 7$ patients in the non-closure group and 6 patients in the closure group had both surgical and general complications

${ }^{\alpha}$ Site of leakage was gastrojejunostomy for 1 patient and duodenal stump for 4 patients

${ }^{\#}$ Site of leakage was duodenal stump for 1 patient

${ }^{\mathbb{I I}}$ Site of bleeding was the abdominal cavity for 3 patients and gastrointestinal tract for 1 patient

$\times$ Site of bleeding was the abdominal cavity for 2 patient and the gastrointestinal tract for 1 patient

$\S$ Small bowel perforation due to gallstone

* 1 patient died of pulmonary infection and respiratory failure

f $\chi^{2}$ test

Table 3 Characteristics of patients with $\mathrm{PH}$

\begin{tabular}{|c|c|c|c|c|c|c|c|c|c|}
\hline Case & Age & Sex & $\begin{array}{l}\text { Interval period } \\
\text { (months) }\end{array}$ & $\begin{array}{l}\text { Whirl } \\
\text { sign }\end{array}$ & $\begin{array}{l}\text { Closure } \\
\text { of PD }\end{array}$ & Procedure of gastrectomy & $\begin{array}{l}\text { Bowel } \\
\text { resection }\end{array}$ & $\begin{array}{l}\text { Type of } \\
\text { surgery }\end{array}$ & Mortality \\
\hline 1 & 58 & Male & 22 & Yes & Yes & Laparoscopy-assisted distal gastrectomy & No & Emergency & No \\
\hline 2 & 65 & Male & 24 & Yes & No & Open distal gastrectomy & No & Emergency & No \\
\hline 3 & 64 & Male & 7 & Yes & No & Open distal gastrectomy & No & Emergency & Yes* \\
\hline 4 & 47 & Female & 1 & Yes & No & Laparoscopy-assisted distal gastrectomy & No & Elective & No \\
\hline 5 & 44 & Female & 7 & Yes & No & Open total gastrectomy & Yes & Emergency & No \\
\hline 6 & 79 & Male & 27 & Yes & No & Open total gastrectomy & No & Emergency & No \\
\hline 7 & 67 & Male & 16 & Yes & No & Open distal gastrectomy & No & Emergency & No \\
\hline 8 & 78 & Male & 6 & Yes & No & Open distal gastrectomy & No & Emergency & No \\
\hline 9 & 66 & Male & 1 & Yes & No & Open distal gastrectomy & Yes & Emergency & No \\
\hline 10 & 60 & Female & 7 & Yes & No & Open distal gastrectomy & No & Elective & No \\
\hline 11 & 47 & Female & 28 & Yes & No & Laparoscopy-assisted total gastrectomy & No & Emergency & No \\
\hline 12 & 50 & Female & 27 & Yes & No & Open distal gastrectomy & Yes & Emergency & No \\
\hline
\end{tabular}

*Died of sepsis caused by bowel necrosis; $P H$, Petersen's hernia; $B M I$, body mass index; $P D$, Petersen's defect 
on CT scans preoperatively. Among them, 10 patients underwent emergency surgery, and two patients underwent elective surgery. The two patients in the elective surgery group were diagnosed with SPH before surgery according to previous diagnostic criteria $[10,11$, 19-21], and they were confirmed to have PH by surgical exploration.

\section{Risk factors for PH and SPH}

Table 4 shows the results of univariate and multivariate analyses to identify the independent risk factors for $\mathrm{PH}$ and SPH. In the multivariate analysis, non-closure of the PD was the only risk factor for $\mathrm{PH}$ and $\mathrm{SPH}$ (odds ratio (OR) 7.72, 95\% CI $1.84-32.35, p=0.006$ ). Sex, age, BMI, previous abdominal surgery, surgical approach, reconstruction type, and the extent of lymphadenectomy were not associated with $\mathrm{PH}$ and SPH occurrence.

\section{Discussion}

Gastric cancer is a major health problem, as it is the second leading cause of cancer death and the fourth most common cancer worldwide [24]. Surgery is a major curative strategy for gastric cancer [24]. A PD is created after gastrectomy with B-2 or R-Y reconstruction. However, there has been no consensus yet on how to deal with it.

The study showed that the rates of PH and SPH were significantly decreased after PD closure. The analysis of the risk factors for PH and SPH additionally validated these findings. Our results were consistent with those of previous studies [8, $21,25]$.

Theoretically, if PDs are completely closed, no PH can occur. However, similar to a previous study [14], one case of PH occurred after we began closing PDs. We found that the $\mathrm{PH}$ patient underwent gastrectomy during the first week when we started to close PDs,

Table 4 Results of univariate and multivariate analyses to identify the independent risk factors for PH and SPH

\begin{tabular}{|c|c|c|c|c|c|c|}
\hline & \multicolumn{2}{|l|}{$\mathrm{PH}$ and $\mathrm{SPH}$} & \multicolumn{2}{|l|}{ Univariate analysis } & \multicolumn{2}{|l|}{ Multivariate analysis } \\
\hline & (No, $n=1178$ ) & (Yes, $n=35$ ) & OR $(95 \% \mathrm{CI})$ & $p$ & OR $(95 \% \mathrm{CI})$ & $p$ \\
\hline \multicolumn{7}{|l|}{ Sex } \\
\hline Female & 355 & 10 & 1.00 (reference) & & & \\
\hline Male & 823 & 25 & $1.08(0.51-2.27)$ & 0.842 & & \\
\hline \multicolumn{7}{|l|}{ Age (years) } \\
\hline$\geq 65$ & 367 & 12 & 1.00 (reference) & & & \\
\hline$<65$ & 811 & 23 & $0.87(0.42-1.76)$ & 0.694 & & \\
\hline \multicolumn{7}{|l|}{ BMI $\left(\mathrm{kg} / \mathrm{m}^{2}\right)$} \\
\hline$\geq 25$ & 925 & 27 & 1.00 (reference) & & & \\
\hline$<25$ & 253 & 8 & $1.08(0.49-2.41)$ & 0.845 & & \\
\hline \multicolumn{7}{|l|}{ Previous abdominal surgery } \\
\hline Yes & 214 & 2 & 1.00 (reference) & & 1.00 (reference) & \\
\hline No & 964 & 33 & $3.66(0.87-15.38)$ & 0.076 & $3.43(0.81-14.45)$ & 0.093 \\
\hline \multicolumn{7}{|l|}{ Surgical approach } \\
\hline Laparoscopy assisted/robot & 160 & 2 & 1.00 (reference) & & & \\
\hline Open & 1018 & 33 & $2.59(0.62-10.91)$ & 0.194 & & \\
\hline \multicolumn{7}{|l|}{ Type of reconstruction } \\
\hline R-Y (total gastrectomy) & 391 & 14 & 1.00 (reference) & & & \\
\hline B-2 (distal gastrectomy) & 787 & 21 & $0.75(0.38-1.48)$ & 0.402 & & \\
\hline \multicolumn{7}{|l|}{ Extent of lymphadenectomy } \\
\hline $\mathrm{D} 1 / \mathrm{D} 1+$ & 222 & 8 & 1.00 (reference) & & & \\
\hline $\mathrm{D} 2 / \mathrm{D} 2+$ & 956 & 27 & $0.79(0.45-6.18)$ & 0.417 & & \\
\hline \multicolumn{7}{|l|}{ Closure of PD } \\
\hline Yes (second period) & 383 & 2 & 1.00 (reference) & & 1.00 (reference) & \\
\hline No (first period) & 795 & 33 & $7.95(1.90-33.30)$ & $0.005^{*}$ & $7.72(1.84-32.35)$ & $0.006^{*}$ \\
\hline
\end{tabular}

Values in parentheses are 95\% confidence intervals. $O R$, odds ratio; $C I$, confidence interval; $P H$, Petersen's hernia; $S P H$, suspected Petersen's hernia; $B M I$, body mass index; $R-Y$, Roux-en-Y reconstruction; $B-2$, Billroth-2 reconstruction; $P D$, Petersen's defect

*Statistically significant difference $(p<0.05)$ 
and there have been no $\mathrm{PH}$ patients in the closure group since then. Both surgeons participating in the study were very well experienced with gastrectomy and far beyond their learning curve for this operation, but this was not necessarily the case for PD closure. Therefore, the reason for this case of PH may be incomplete closure of the PD during primary surgery [26]. Another explanation is that defects may open after the loss of mesenteric fat, leading to the formation of $\mathrm{PH}$ [27]. Therefore, although the closure of all mesenteric defects cannot completely prevent $\mathrm{PH}$, current studies have shown that it may decrease the incidence rate.

To our knowledge, there has been no study that specifically investigated the rate of $\mathrm{PH}$ after gastrectomy for gastric cancer. Several studies examining internal hernias after gastrectomy for gastric cancer have been conducted. The overall rate of internal hernia (they were all PDs in this study) was $1.0 \%$ in our study, and the rate ranged from $0.19-5.0 \%$ in previous studies $[1,7,14,21]$. The rate of internal hernia varied greatly among different studies. These differences may be caused by different inclusion groups, diagnostic criteria, follow-up periods, laparoscopy proportions, and mesenteric defect closures [1]. The rate of internal hernia in this study was lower than that in most previous studies. The possible reason is that we routinely closed the jejunojejunostomy mesenteric defects in all patients, and no internal hernia was found at these defects in this study; however, most authors left the defects open before they changed their technique to close all mesenteric defects, and many internal hernias were located at jejunojejunostomy mesenteric defects in their studies. In a study conducted by Miyagaki et al. [14], all gastrectomies, regardless of reconstruction method or gastrectomy type, were investigated, including patients with little possibility of internal hernia such as those who underwent esophagogastrostomy and Billroth-1 reconstruction. The 3-year incidence rate of internal hernia in their study was $0.19 \%$, which was the lowest in literature.

In previous studies, laparoscopic surgery was found to be a risk factor for $\mathrm{PH}[1,7,14,21,28]$. The possible reason was fewer adhesions $[1,14]$. However, similar to a previous study [8], laparoscopic surgery was not a risk factor for $\mathrm{PH}$ in the present study. A possible explanation was that we adopted laparoscopy-assisted surgery in most cases. However, most authors mainly adopted total laparoscopic surgery in previous studies. Laparoscopy-assisted surgery may result in more adhesions than total laparoscopic surgery.

In previous studies on the effect of the closure of mesenteric defects after gastrectomy for gastric cancer, the internal hernia was defined as the only endpoint, but if suspected internal hernias were not included, the effect of mesenteric defect closure could have been overlooked. Due to its rare incidence and nonspecific symptoms, it is difficult to diagnose $\mathrm{PH}$ preoperatively.
CT scans have become the main method to diagnose PH preoperatively [10], and some authors suggest that the most predictive signs of PH included the "whirl sign" and small bowel obstruction on $\mathrm{CT}$ scans (sensitivity $78-100 \%$, specificity $80-90 \%)$ [3, 11, 19, 20]. Kang et al. [21] even used the "whirl sign" as a diagnostic criterion for internal hernia in their study. In the present study, 2 patients were considered to have SPH according to previous diagnostic criteria $[10,11,19-21]$ before surgery, and they were finally confirmed to be PH by surgical exploration. Following the same diagnostic criteria, there were $23 \mathrm{SPH}$ patients in our study. There is a strong possibility that some of these patients had $\mathrm{PH}$, although they were not confirmed by surgery. These patients were managed non-operatively because they had no signs of bowel necrosis, and they were reluctant to receive surgery, or surgery was not physically possible.

There is concern that closure of mesenteric defects may be associated with a higher rate of postoperative complications such as mesenteric hematomas and bleeding. However, in our study, there was no difference in the rate of complications within 30 days between the non-closure and closure groups, indicating that PD closure did not increase early postoperative complications.

The strengths of the study were that it followed a standardized surgical protocol and included two distinct groups for comparison. Both surgeons participating in the study were well and equally experienced in gastrectomy for gastric cancer. The limitations of the study include that it was a retrospective study conducted in a single center. Another potential limitation of the study was that the follow-up duration was different between the two groups. However, the rate of $\mathrm{PH}$ seems to be highest within 1-2 years after operation [29-31], corresponding to the time of the greatest weight loss [3]. All the patients in the closure group were followed up for at least 26 months or until death, we would not expect a large number of additional PHs in this group. A multicenter prospective study is required to evaluate patients with the closure of all mesenteric defects during gastrectomy, including postoperative complications and quality of life.

In conclusion, PD closure is recommended after gastrectomy for gastric cancer, as the rates of $\mathrm{PH}$ and $\mathrm{SPH}$ were significantly decreased, while the procedure did not significantly increase postoperative complications.

Acknowledgment The authors thank the substantial work of the Volunteer Team of Gastric Cancer Surgery (VOLTGA) West China Hospital, Sichuan University, China, for the establishment and updating of the gastric cancer database.

Authors' contributions Study conception and design: Jian-kun Hu, Tao Pan, Hui Wang, and Xin-zu Chen. Acquisition of data: Tao Pan, Hui Wang, Kai-Liu, Xiao-long Chen, Wei-han Zhang, Xin-zu Chen, Kun 
Yang, Bo Zhang, Jian-Kun Hu, and Zong-guang Zhou. Analysis and interpretation of data: Tao Pan, Hui Wang, Kai-Liu, Xiao-long Chen, and Wei-han Zhang. Drafting of the manuscript: Tao Pan, Hui Wang. Critical revision of the manuscript: Tao Pan, Hui Wang, Kai Liu, Xin-zu Chen, Wei-han Zhang, Xiao-long Chen, and Kun Yang. Final approval of the version to be published: Jian-kun Hu.

Funding This study was funded by (1) the National Natural Science Foundation of China, No. 81702366; (2) Foundation of Science \& Technology Department of Sichuan Province (2019YFS0255); (3) 1.3.5 Project for Disciplines of Excellence, West China Hospital, Sichuan University, No. ZY2017304; and (4) Sichuan Province Cadre Health Care Research Project (No.2017-114).

Availability of data and material The datasets used and/or analyzed during the current study are available from the corresponding author on reasonable request.

\section{Compliance with ethical standards}

Conflict of interest The authors declare that they have no conflict of interest.

Ethical approval This study was based on the information gathered from the database of the Surgical Gastric Cancer Patient Registry of West China Hospital (WCH-SGCPR) under the registration number: WCH-SGCPR-2019-10. The establishment of this database was approved by the Research Ethics Committee of West China Hospital. Informed consent of individual patients were waived because of the retrospective nature of the analysis.

\section{Consent for publication Not applicable.}

\section{Code availability Not applicable.}

Open Access This article is licensed under a Creative Commons Attribution 4.0 International License, which permits use, sharing, adaptation, distribution and reproduction in any medium or format, as long as you give appropriate credit to the original author(s) and the source, provide a link to the Creative Commons licence, and indicate if changes were made. The images or other third party material in this article are included in the article's Creative Commons licence, unless indicated otherwise in a credit line to the material. If material is not included in the article's Creative Commons licence and your intended use is not permitted by statutory regulation or exceeds the permitted use, you will need to obtain permission directly from the copyright holder. To view a copy of this licence, visit http://creativecommons.org/licenses/by/4.0/.

\section{References}

1. Han WH, Eom BW, Yoon HM, Kim YW, Ryu KW (2018) Clinical characteristics and surgical outcomes of internal hernia after gastrectomy in gastric cancer patients: retrospective case control study. Surg Endosc 33:2873-2879. https://doi.org/10.1007/s00464-0186584-3

2. Steele KE, Prokopowicz GP, Magnuson T, Lidor A, Schweitzer M (2008) Laparoscopic antecolic Roux-en-Y gastric bypass with closure of internal defects leads to fewer internal hernias than the retrocolic approach. Surg Endosc 22(9):2056-2061. https://doi. org/10.1007/s00464-008-9749-7
3. Stenberg E, Szabo E, Ågren G, Ottosson J, Marsk R, Lönroth H, Boman L, Magnuson A, Thorell A, Näslund I (2016) Closure of mesenteric defects in laparoscopic gastric bypass: a multicentre, randomised, parallel, open-label trial. Lancet 387(10026):13971404. https://doi.org/10.1016/s0140-6736(15)01126-5

4. Geubbels N, Lijftogt N, Fiocco M, van Leersum NJ, Wouters MW, de Brauw LM (2015) Meta-analysis of internal herniation after gastric bypass surgery. Br J Surg 102(5):451-460. https://doi.org/ 10.1002/bjs. 9738

5. Amor IB, Kassir R, Debs T, Aldeghaither S, Petrucciani N, Nunziante M, Baqué P, Almunifi A, Gugenheim J (2019) Impact of mesenteric defect closure during laparoscopic Roux-en-Y gastric bypass (LRYGB): a retrospective study for a total of 2093 LRYGB. Obes Surg 29:3342-3347. https://doi.org/10.1007/s11695-01904000-5

6. Blockhuys M, Gypen B, Heyman S, Valk J, van Sprundel F, Hendrickx L (2019) Internal hernia after laparoscopic gastric bypass: effect of closure of the Petersen defect - single-center study. Obes Surg 29(1):70-75. https://doi.org/10.1007/s11695-018-34729

7. Kojima K, Inokuchi M, Kato K, Motoyama K, Sugihara K (2014) Petersen's hernia after laparoscopic distal gastrectomy with Rouxen-Y reconstruction for gastric cancer. Gastric Cancer 17(1):146151. https://doi.org/10.1007/s10120-013-0256-8

8. Yoshikawa K, Shimada M, Kurita N, Sato H, Iwata T, Higashijima J, Chikakiyo M, Nishi M, Kashihara H, Takasu C, Matsumoto N, Eto S (2014) Characteristics of internal hernia after gastrectomy with Roux-en-Y reconstruction for gastric cancer. Surg Endosc 28(6):1774-1778. https://doi.org/10.1007/s00464-013-3384-7

9. Comeau E, Gagner M, Inabnet WB, Herron DM, Quinn TM, Pomp A (2005) Symptomatic internal hernias after laparoscopic bariatric surgery. Surg Endosc 19(1):34-39. https://doi.org/10.1007/s00464003-8515-0

10. Ederveen JC, van Berckel MMG, Nienhuijs SW, Weber RJP, Nederend J (2018) Predictive value of abdominal CT in evaluating internal herniation after bariatric laparoscopic Roux-en-Y gastric bypass. Br J Surg 105(12):1623-1629. https://doi.org/10.1002/ bjs. 10886

11. Lockhart ME, Tessler FN, Canon CL, Smith JK, Larrison MC, Fineberg NS, Roy BP, Clements RH (2007) Internal hernia after gastric bypass: sensitivity and specificity of seven CT signs with surgical correlation and controls. AJR Am J Roentgenol 188(3): 745-750. https://doi.org/10.2214/AJR.06.0541

12. Hwang RF, Swartz DE, Felix EL (2004) Causes of small bowel obstruction after laparoscopic gastric bypass. Surg Endosc 18(11): 1631-1635. https://doi.org/10.1007/s00464-004-8804-2

13. Brolin RE, Kella VN (2013) Impact of complete mesenteric closure on small bowel obstruction and internal mesenteric hernia after laparoscopic Roux-en-Y gastric bypass. Surg Obes Relat Dis 9(6): 850-854. https://doi.org/10.1016/j.soard.2012.11.007

14. Miyagaki H, Takiguchi S, Kurokawa Y, Hirao M, Tamura S, Nishida T, Kimura Y, Fujiwara Y, Mori M, Doki Y (2012) Recent trend of internal hernia occurrence after gastrectomy for gastric cancer. World J Surg 36(4):851-857. https://doi.org/10. 1007/s00268-012-1479-2

15. Li H, Gong Y, Han J, Zhang S, Chen S, Xu X, Lu Z, Yin X (2020) Interrupted time-series analysis to evaluate the impact of a national antimicrobial stewardship campaign on antibiotic prescribing: a typical practice in China's primary care. Clin Infect Dis. https:// doi.org/10.1093/cid/ciaa962

16. Washington $\mathrm{K}$ (2010) 7th edition of the AJCC cancer staging manual: stomach. Ann Surg Oncol 17(12):3077-3079. https://doi.org/ 10.1245/s10434-010-1362-z

17. Sano T, Aiko T (2011) New Japanese classifications and treatment guidelines for gastric cancer: revision concepts and major revised 
points. Gastric Cancer 14(2):97-100. https://doi.org/10.1007/ s10120-011-0040-6

18. Japanese Gastric Cancer A (2017) Japanese gastric cancer treatment guidelines 2014 (ver. 4). Gastric Cancer 20(1):1-19. https://doi.org/ 10.1007/s10120-016-0622-4

19. Iannuccilli JD, Grand D, Murphy BL, Evangelista P, Roye GD, Mayo-Smith W (2009) Sensitivity and specificity of eight CT signs in the preoperative diagnosis of internal mesenteric hernia following Roux-en-Y gastric bypass surgery. Clin Radiol 64(4):373-380. https://doi.org/10.1016/j.crad.2008.10.008

20. Lanzetta MM, Masserelli A, Addeo G, Cozzi D, Maggialetti N, Danti G, Bartolini L, Pradella S, Giovagnoni A, Miele V (2019) Internal hernias: a difficult diagnostic challenge. Review of CT signs and clinical findings. Acta Biomed 90(5-S):20-37. https:// doi.org/10.23750/abm.v90i5-S.8344

21. Kang KM, Cho YS, Min SH, Lee Y, Park KB, Park YS, Ahn SH, Park DJ, Kim HH (2019) Internal hernia after gastrectomy for gastric cancer in minimally invasive surgery era. Gastric Cancer 22: 1009-1015. https://doi.org/10.1007/s10120-019-00931-1

22. Dindo D, Demartines N, Clavien PA (2004) Classification of surgical complications: a new proposal with evaluation in a cohort of 6336 patients and results of a survey. Ann Surg 240(2):205-213. https://doi.org/10.1097/01.sla.0000133083.54934.ae

23. Kubota T, Hiki N, Sano T, Nomura S, Nunobe S, Kumagai K, Aikou S, Watanabe R, Kosuga T, Yamaguchi T (2014) Prognostic significance of complications after curative surgery for gastric cancer. Ann Surg Oncol 21(3):891-898. https://doi.org/10. 1245/s10434-013-3384-9

24. Van Cutsem E, Sagaert X, Topal B, Haustermans K, Prenen H (2016) Gastric cancer. Lancet 388(10060):2654-2664. https://doi. org/10.1016/s0140-6736(16)30354-3

25. Kelly KJ, Allen PJ, Brennan MF, Gollub MJ, Coit DG, Strong VE (2013) Internal hernia after gastrectomy for cancer with Roux-Y reconstruction. Surgery 154(2):305-311. https://doi.org/10.1016/j. surg.2013.04.027
26. Toriumi T, Makuuchi R, Kamiya S, Tanizawa Y, Bando E, Terashima M (2019) Obesity is a risk factor for internal hernia after laparoscopic or robot-assisted gastrectomy with mesenteric defect closure for gastric cancer. Surg Endosc 34:436-442. https://doi.org/ 10.1007/s00464-019-06787-x

27. Chowbey P, Baijal M, Kantharia NS, Khullar R, Sharma A, Soni V (2016) Mesenteric defect closure decreases the incidence of internal hernias following laparoscopic Roux-En-Y gastric bypass: a retrospective cohort study. Obes Surg 26(9):2029-2034. https://doi.org/ 10.1007/s11695-016-2049-8

28. Hosoya Y, Lefor A, Ui T, Haruta H, Kurashina K, Saito S, Zuiki T, Sata N, Yasuda Y (2011) Internal hernia after laparoscopic gastric resection with antecolic Roux-en-Y reconstruction for gastric cancer. Surg Endosc 25(10):3400-3404. https://doi.org/10.1007/ s00464-011-1739-5

29. Rodriguez A, Mosti M, Sierra M, Perez-Johnson R, Flores S, Dominguez G, Sanchez H, Zarco A, Romay K, Herrera MF (2010) Small bowel obstruction after antecolic and antegastric laparoscopic Roux-en-Y gastric bypass: could the incidence be reduced? Obes Surg 20(10):1380-1384. https://doi.org/10.1007/ s11695-010-0164-5

30. de la Cruz-Munoz N, Cabrera JC, Cuesta M, Hartnett S, Rojas R (2011) Closure of mesenteric defect can lead to decrease in internal hernias after Roux-en-Y gastric bypass. Surg Obes Relat Dis 7(2): 176-180. https://doi.org/10.1016/j.soard.2010.10.003

31. Ahmed AR, Rickards G, Husain S, Johnson J, Boss T, O'Malley W (2007) Trends in internal hernia incidence after laparoscopic Rouxen-Y gastric bypass. Obes Surg 17(12):1563-1566. https://doi.org/ $10.1007 / \mathrm{s} 11695-007-9260-6$

Publisher's note Springer Nature remains neutral with regard to jurisdictional claims in published maps and institutional affiliations. 